\title{
Prevalence of migraine in Upper Egypt
}

\author{
Hamdy N. El-Tallawy', Wafaa M. Farghaly', Mohamed A. Abdelhamed ${ }^{1 *}$, Reda Badry', Tarek A. Rageh',
}

Wael T. Soliman ${ }^{3}$, Khaled O. Abdulghani ${ }^{4}$, Mahmoud Hassan², Sayed Sobhy ${ }^{3}$ and Ghaydaa A. Shehata ${ }^{1}$

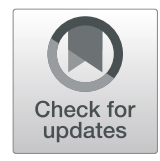

\begin{abstract}
Background: Migraine is a significant health problem due its frequency and accompanying morbidity.

Objectives: This study aims to estimate the prevalence of migraine headache among the population of Al-Quseir city (Upper Egypt) and its impact on the patients' life.

Methods: This study is part of a door-to-door survey of major neurological disorders in Al-Quseir city, Red Sea Governorate. All inhabitants ( $n=33,285$ persons) were screened through door to door by three specialists of neurology. Then, positive cases were subjected to clinical and neurological examination by three staff members of neurology each separately. Respondents were identified as suffering from migraine with aura, migraine without aura, and probable migraine as defined by the diagnostic criteria of the International Headache Society (IHS). Migraine Disability Assessment Scale (MIDAS) questionnaire was used to assess the impact of the disease on the patients' daily life.

Results: We identified 911 patients suffering from migraine. The lifetime prevalence was 3.38/100 with male prevalence of 1.95/100 and female prevalence of 4.8/100. The highest prevalence figures were found during early adult life (18-40 years) among both genders reaching a total prevalence of 4.77/100 (2.89/100 for male and 6.53/100 for female). Among migraine patients, most of the attacks recorded were of moderate to severe intensity (97\%) although virtually $66 \%$ of migraine patients reported that headache significantly interfered with their daily activities.
\end{abstract}

Conclusion: Lifetime prevalence of migraine is 3.38/100. Migraine headache has a deleterious impact on the patient's functional and wellbeing.

Keywords: Epidemiology, Migraine, Al-Quseir, Egypt

\section{Introduction}

The term "migraine" is derived from the Greek expression "Hemikranion" which means a half skull [1]. Migraine is a headache disorder with attacks of pulsating pain usually occurring on one side of the cranium. It is frequently accompanied by symptoms such as nausea, vomiting, and sensitivity to light and noise and is aggravated by movement [2]. Migraine is most prevalent during the peak productive years and has a negative influence on the quality of life. Health economic studies have consistently documented the high medical care use and indirect costs associated with this disabling medical condition [3, 4]. Commonly starting at puberty, migraine mostly affects those aged between 35 and 45 years but can trouble much younger people,

\footnotetext{
*Correspondence: moh78_abdelhamed@yahoo.com

${ }^{1}$ Department of Neurology, Assiut University, Assiut, Egypt

Full list of author information is available at the end of the article
}

including children. Remarkably, despite high levels of temporal disability, many migraineurs have never consulted a physician for the problem, which in turn has introduced selection bias in migraine studies based on patients who seek treatment rather than persons from the general population [5]. Although numerous studies of migraine prevalence have been published, reviews of the epidemiological literature have shown a large variation in the prevalence rates (ranging from 1. 4 to 8\%) [6, 7].

This study aims to estimate the prevalence of migraine headache among the population of Al-Quseir city, Red Sea Governorate, Upper Egypt, and to determine migraine-related disability and treatment gap.

\section{Population and methods}

This study is part of a door-to-door survey of major neurological disorders that was conducted in Al-Quseir city (Red Sea Governerate) over a period of about $2 \frac{1}{2}$ years (July 1, 2009, to January 31, 2012). This project was carried 
Table 1 Age and sex lifetime prevalence of migraine among the studied population

\begin{tabular}{lllllll}
\hline Age group & \multicolumn{2}{l}{ Migraine patients } & & \multicolumn{2}{l}{ Total population } \\
\cline { 2 - 3 } & Male, number (prevalence \%) & Female, number (prevalence \%) & Total, number (prevalence \%; 95\% Cl) & Male & Female & Total \\
\hline 6 to $<12$ years & $20(0.99)$ & $14(0.76)$ & $34(0.88 ; 0.59-1.17)$ & 2025 & 1837 & 3862 \\
12 to $<18$ years & $26(1.26)$ & $76(3.9)$ & $102(2.54 ; 2.02-3.03)$ & 2065 & 1949 & 4014 \\
18 to $<40$ years & $182(2.89)$ & $438(6.53)$ & $620(4.77 ; 4.4-5.14)$ & 6300 & 6709 & 13,009 \\
40 to $<60$ & $33(1.09)$ & $122(3.99)$ & $155(2.55 ; 2.15-2.95)$ & 3021 & 3056 & 6077 \\
Total & $261(1.95)$ & $650(4.80)$ & $911(3.38 ; 3.16-3.6)$ & 13,410 & 13,551 & 26,961 \\
\hline
\end{tabular}

out on eligible inhabitants who had been living in Al-Quseir city, for at least 6 months at the time of the study. This study was approved by the Local Ethics Committee of Assiut University and Ministry of Health (Red Sea Area Health Service) prior to commencement. All participants gave consent before inclusion to the study. The study area, Al-Quseir city, is a representative city of those lying on Red Sea. Al-Quseir city is the second city in the Red Sea Governorate as regards the number of population [8].

\section{Stage of screening}

Sample size of 33,285 persons were screened through door to door (every door) by three specialists of neurology using a standardized Arabic questionnaire, which the authors used in a previous validated study $[9,10]$. Fifteen female social workers accompanied the specialists during house visits to collect demographic data.

Then, positive cases were subjected to meticulous clinical and neurological examination for case ascertainment.

\section{Stage of case ascertainment}

Respondents were identified as suffering from migraine with aura, migraine without aura, and probable migraine according to the diagnostic criteria of the International Headache Society (IHS) (2004).

Then, the frequency of attacks was recorded using four grades (less than 1 attack per month, 1-3 attacks per month, 1-3 attacks per week, attacks every day). The intensity of attacks was recorded using three grades (mild, moderate, and severe) according to the
International Classification of Headache Society 2004 [2]. Functional disability was assessed through evaluation of the impact of the disease on the patient's daily life using Migraine Disability Assessment Scale (MIDAS) [11]. Lastly, patients were asked about medical consultations and medicines used during and in between attacks.

\section{Treatment gap}

Treatment gap is the number of patients with active migraine, not on treatment, or inadequately treated, expressed as a percentage of the total number with active migraine [14].

\section{Statistical analysis}

The data were coded and verified prior to data entry. Data analysis was carried out by using SPSS version 16 (SPSS Inc., Chicago, IL, USA), Excel (Microsoft Corporation, Redmond, WA, USA), and EpiCalc 2000 (Microsoft Corporation, Redmond, WA, USA). Descriptive statistics were calculated. Estimation of prevalence rates was done by dividing the total number of headache suffers over the total population at risk.

\section{Results}

From the total number of 33,285 persons, those were screened through door to door, we identified 911 patients suffering from migraine (650 females and 261 males). The lifetime prevalence rate was 3.38/100 (95\% confidence interval [CI] 3. 16-3.6), 1.9/100 in males and 4.8/100 in females, with male to female ratio of 1:2.5 (Table 1 ). The prevalence of migraine was $4.77 \%$ in the 18 - to < 40 -year

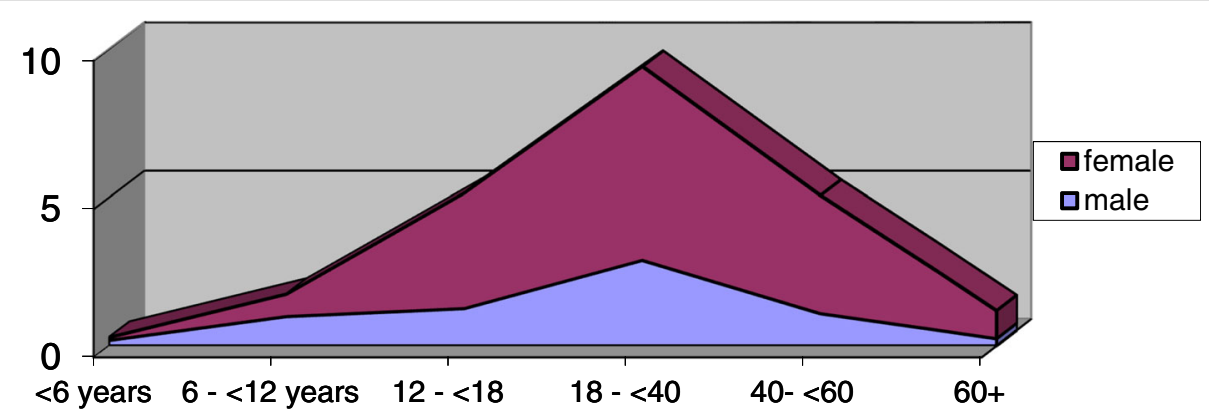

Fig. 1 Linear trend of age- and gender-specific prevalence of migraine among studied patients 


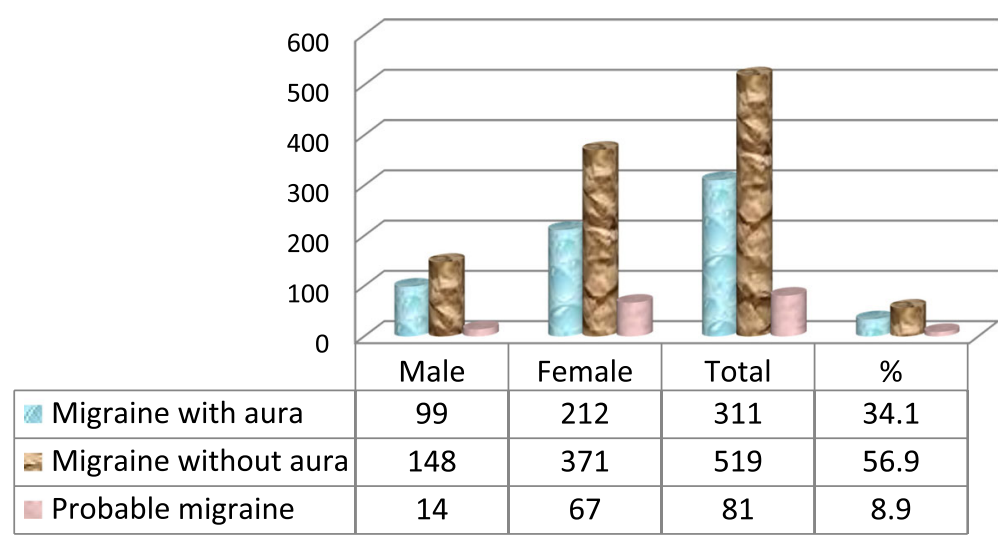

Fig. 2 Frequency of migraine subtypes among the studied population

stratum which was significantly higher in both genders than other age groups $(p<0.01)$ (Table 1, Fig. 1).

Analysis of the type of migrainous attacks revealed that $56.9 \%$ of patients $(n=519)$ had migraine without aura, while $34.1 \%$ of patients $(n=311)$ suffer from migraine with aura, and $8.9 \%(n=81)$ had probable migraine (Fig. 2).

Evaluation of the frequency of attacks revealed that the majority of patients (72.1\%) suffer from 1-3 attacks/month (Table 2). Regarding pain intensity of the attacks, females recorded insignificantly higher rate $(55.4 \%)$ of severe migraine attacks than males (47.9\%) (Table 2).

Assessment of disability among migraineurs using MIDAS showed that $42.4 \%$ had severe disability (grade IV) with no statistically significant difference between male and female patients (Table 3).

Regarding treatment of acute attacks, it was found that $59 \%$ of patients $(n=548)$ use combined analgesic/anti-inflammatory preparations, $19 \%$ use simple analgesics, and $21 \%$ use ergot preparations, while only $8.1 \%$ use triptan (Fig. 3). Regarding prophylactic treatment in between attacks, it was found that the treatment gap among migraineurs was $91.5 \%$, i.e., most detected migraineurs (91.5\%) were receiving no prophylactic treatment.

Table 2 Features of migraine attacks among the studied population

\begin{tabular}{lll}
\hline & Male, number 261 (\%) & Female, number $650(\%)$ \\
\hline Frequency of attacks & \\
$1-3 /$ month & $191(73.2 \%)$ & $466(71.7 \%)$ \\
$1-3 /$ week & $62(23.7 \%)$ & $159(24.5 \%)$ \\
$1 /$ day & $8(3.1 \%)$ & $25(3.8 \%)$ \\
Pain intensity & & \\
Moderate & $136(52.1 \%)$ & $290(44.6 \%)$ \\
Severe & $125(47.9 \%)$ & $360(55.4 \%)$ \\
\hline
\end{tabular}

\section{Discussion}

Although, a door-to-door approach in estimating the prevalence of migraine is difficult and time consuming, it is more accurate than hospital-based studies as the majority of patients do not seek medical advice for self-limited paroxysmal disorders [12, 13]. Moreover, personal interview by a neurologist is better than diagnoses based on self-assessment by patients through questionnaires, as it is devoid of any recall bias and is more sensitive to detect comorbidities [13]. In the present study, the lifetime prevalence rate of migraine was $3.38 \%$, with the highest figure $(4.77 \%)$ found among young adults (18 to $<40$ years). Migraine prevalence in the current study is near the global data of WHO estimates which mentioned that migraine appears somewhat less prevalent, but still common, in Asia (3\% of men and $10 \%$ of women) and in Africa (3-7\% in community-based studies) [14]. However, epidemiological studies had shown that migraine seems to be more prevalent in Europe (14.8\%) and North America (11.1\%) than it is in Africa (4\%) [15]. Although numerous studies of migraine prevalence have been published, reviews of the epidemiological literatures have shown large variation in the prevalence rates, which is mostly explained by differences in

Table 3 MIDAS grading in patients with migraine

\begin{tabular}{llll}
\hline MIDAS grade & $\begin{array}{l}\text { Male, number } \\
(\%)\end{array}$ & $\begin{array}{l}\text { Female, number } \\
(\%)\end{array}$ & $\begin{array}{l}\text { Total, number } \\
(\%)\end{array}$ \\
\hline $\begin{array}{l}\text { I Minimal } \\
\text { score 0-5 }\end{array}$ & $30(11.5 \%)$ & $63(9.7 \%)$ & $93(10.2 \%)$ \\
$\begin{array}{l}\text { II Mild } \\
\text { score 6-10 }\end{array}$ & $69(26.4 \%)$ & $129(19.8 \%)$ & $198(21.7 \%)$ \\
$\begin{array}{l}\text { III Moderate } \\
\text { score 11-20 }\end{array}$ & $70(26.8 \%)$ & $164(25.2 \%)$ & $234(25.7 \%)$ \\
$\begin{array}{l}\text { IV Severe } \\
\text { score } \geq 21\end{array}$ & $92(35.2 \%)$ & $294(45.2 \%)$ & $386(42.4 \%)$ \\
\hline
\end{tabular}




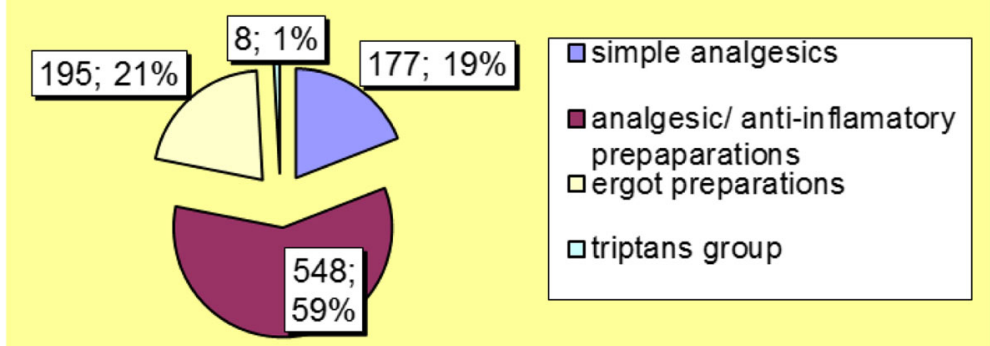

Fig. 3 Drug options used among studied migrainous patients

socio-demographic profiles of the study subjects, survey methods, and case definition $[6,7,11,16]$.

In the present study, migraine was found to be more prevalent among females $(4.8 \%)$ than males $(1.95 \%)$ with male to female ratio of 1:2.5, and this was more obvious around puberty (12 to < 18 years) where male prevalence was 1.26 while female prevalence was 3.9 as mentioned in Table 1. Increased prevalence of migraine among females around puberty could be attributed to hormonal differences particularly related to the newly encountered menstrual cycles, a condition referred to as estrogenwithdrawal headache by the International Classification of Headache Disorders (ICHD) [2, 17].

As regards the age-specific prevalence among different age groups, we found that the youngest recorded case of migraine was 6 years. Prevalence then increases steadily to reach its peak at young adults (18 to $<40$ years) and then declines again at late adult life (Table 1). These results are partially consistent with most studies on migraine prevalence, which have reported variation among different age groups, with prevalence figures following an inverted U-shaped distribution, increasing from age 15 to 18 , peaking during the third and early fourth decades of life and declining thereafter $[18,19]$.

In the present study, migraine without aura (57\%) was more common than migraine with aura (34\%). This was in agreement with Houinato et al. [20] and Zivadinov et al. [21] who found that migraine without aura was the most frequent form $(67.5 \%$ and $62 \%$ respectively).

The MIDAS may provide a practical tool to understand the impact of migraine and suggest treatment recommendation [22]. Among studied migraineurs, it was found that about $2 / 3(68 \%)$ of patients had moderate (26\% grade III) to severe disability ( $42 \%$ grade IV) (Table 3). These findings are consistent with the Global Migraine and Zolmitriptan evaluation (MAZE) survey, which states that the migraine patients with grade III or IV was found to be as 54\% in France, 47\% in England, $48 \%$ in Germany, $56 \%$ in the USA, and $61 \%$ in Italy [23].

Furthermore, besides this severe disability finding, all migraineurs in the present study reported moderate to severe intensity of their migraine attacks. Despite this marked disability and its impact on daily activity of migraineurs, particularly during their reproductive age period (18-40 years), prophylactic treatment was only administered by $8.5 \%$ of patients. This yields a very wide treatment gap of $91.5 \%$. This heavy burden of migraine disability, besides the very wide treatment gap, might throw some light on this major health problem and necessitates more public awareness and the need for prophylactic treatment.

The determination of migraine treatment gap is vital for health care planning, both on a public health level and an individual level. This treatment gap is a major cause of suffering and contributes to the socioeconomic burden of the disease. In the present study, treatment gap is $91.5 \%$.

\section{Conclusion}

The lifetime prevalence of migraine in $\mathrm{Al}$-Quseir was $3.38 / 100$ with male prevalence of $1.95 / 100$ and female prevalence of $4.8 / 100$. The highest prevalence figures were found during early adult life (18-40 years) among both genders reaching a total prevalence of $4.77 / 100$ (2.89/100 for male and 6.53/100 for female).

\section{Abbreviations}

Cl: Confidence interval; HIS: International Headache Society; MIDAS: Migraine Disability Assessment Scale

\section{Acknowledgements}

We acknowledge the hard work of the social workers, who participate in this work.

\section{Funding}

There is no source of funding for the research.

Availability of data and materials

Supporting the results of this article are included within the article.

\section{Authors' contributions}

$H N$, WMF, MAA, SS, and TR contributed to the data collection. RB and MH analyzed the data and along with WTS and KOM interpreted the data.

Further, GS completed the first draft of the article. All authors were involved in drafting the article or revising it critically for important intellectual content, and all authors approved the final version to be published. 


\section{Ethics approval and consent to participate}

The study was approved from the institutional ethics committee of Faculty of medicine, Assiut University. Ethics approval number R0289N2010 at 19th of June, 2015. A written consent was taken from all of the participants after explaining the details, benefits as well as risks to them.

\section{Consent for publication}

Is not applicable in this section.

\section{Competing interests}

The authors declare that they have no competing interests.

\section{Publisher's Note}

Springer Nature remains neutral with regard to jurisdictional claims in published maps and institutional affiliations.

\section{Author details}

${ }^{1}$ Department of Neurology, Assiut University, Assiut, Egypt. ${ }^{2}$ Department of Neurology, Al Azhar University, Assiut branch, Assiut, Egypt. ${ }^{3}$ Department of Neurology, El Minia University, Minya, Egypt. ${ }^{4}$ Department of Neurology, Helwan University School of Medicine, Helwan, Egypt.

Received: 6 October 2018 Accepted: 5 February 2019

Published online: 26 February 2019

\section{References}

1. Silberstein SD. Practice parameter: evidence-based guidelines for migraine headache (an evidence based review): report of the Quality Standards Subcommittee of the American Academy of Neurology. Neurology. 2000;55:754-62

2. Headache Classification Committee. The international classification of headache disorders (2nd edition). Cephalalgia. 2004;24:1-160.

3. Bigal M, Krymchantowski A, Rapoport A, et al. Prophylactic migraine therapy: emerging treatment options. Curr Pain Headache Rep. 2004;8:178-84

4. Goldberg LD. The cost of migraine and its treatment. Am J Manag Care 2005;11:S62-7

5. Sheffield RE. Migraine prevalence: a literature review. Headache. 1998;38:595-601

6. Natoli JL, Manack A, Dean B, Butler Q, Turkel CC, Stovner L, Lipton RB. Global prevalence of chronic migraine: a systematic review. Cephalalgia. 2010;30(5):599-609.

7. Pfaffenrath $\mathrm{V}$, Fendrich $\mathrm{K}$, Vennemann M, Meisinger C, Ladwig K-H, Evers S, Straube A, Hoffmann W, Berger K. Regional variations in the prevalence of migraine and tension-type headache applying the new HIS. Cephalalgia. 2009;29:48.

8. Saed MG, Aly SM, Karim A Masood, editors. Red Sea Governorate achievement index. 2012. [Arabic].

9. El Tallawy HN, Farghaly WM, Rageh TA, Shehata GA, Metwaly NA Abo elftoh NA, Hegazy MA, et al. Epidemiology of major neurological disorders project in Al Kharga district, New Valley, Egypt. Neuroepidemiology. 2010a;35(4):291-7.

10. El Tallawy HN, Farghaly WM, Metwaly NA, Rageh TA, Shehata GA, Abo elftoh NA, Hegazy MA et al. Door to door survey of major neurological disorders project in Al Kharga district, New Valley, Egypt: methodological aspects. Neuroepidemiology. 2010b;35(4):291-297.

11. Stewart W, Shechter A, Rasmussen B. Migraine prevalence: a review of population-based studies. Neurology. 1994;44(suppl 4):S17-23.

12. Fernandes PT, Salgado PC, Naronha AL, de Boer HM, Prilipko L, Sander JW, Li LM. Epilepsy stigma perception in an urban area of a limited-resource country. Epilepsy Behav. 2007;11:25-32.

13. Nachit-Ouinekh F, Chrysostome V, Henry P, Sourgen C, Dartiques JE, El hasanoui A. Variability of reported headache symptoms and diagnosis of migraine at 12 months. Cephalalgia. 2005;25:117-23.

14. World Health Organization, Headache disorders. Fact sheet N_277, 2004

15. Rigmor J, Lars J. Epidemiology and comorbidity of headache. Lancet Neurol. 2008;7:354-61.

16. Leonardi M, Steiner T, Scher A, Lipton R. The global burden of migraine: measuring disability in headache disorders with WHO's classification of functioning, disability and health (ICF). J Headache Pain. 2005;6:429-40.
17. Misakian A, Langer R, Bensenor I, Manson JE, Buring JE, Rexrode KM Postmenopausal hormone therapy and migraine headache. J Women's Health (Larchmt). 2003;12:1027-36.

18. Lipton $\mathrm{R}$, and Bigal M. Migraine: epidemiology, impact, and risk factors for progression. Headache J Head Face Pain. 2005; Vol. 45, Iss. s1.

19. Tepper SJ, Dahlof C, Dowson A, Newman L, Mansbach H, Jones M, Pham B, Webster C, Salonen R. Prevalence and diagnosis of migraine in patients consulting their primary care physician with a complaint of headache: data from the landmark study. Headache. 2004;44:856-64.

20. Houinato D, Adoukonou T, Ntsiba F, Adjien C, Avodé DG, Preux PM. Prevalence of migraine in rural community in South Benin. Cephalalgia. 2010;30:62-7.

21. Zivadinov R, Willheim K, Sepic-Grahovac D, Jurjevic A, Bucuk M, Brnabic-Razmilic O, Rolia G, et al. Migraine and tension type headache in Croatia: a population-based survey of precipitating factors. Cephalalgia. 2003;23:336-43.

22. Dodick D, Lipton RB, Martin V, Papademetrious V, Rosamond W, MassenVanDen Brick A, Loutfi H, Triptan Cardiovascular Safety Expert Panel, et al. Consensus statement: cardiovascular safety profile of triptans (5-HT agonists) in the acute treatment of migraine. Headache. 2004:44:414-25.

23. MacGregor E, Brandes J, Eikermann A. Migraine prevalence and treatment patterns: the global Migraine and Zolmitriptan Evaluation survey. Headache. 2003:43:19-26.

\section{Submit your manuscript to a SpringerOpen ${ }^{\circ}$ journal and benefit from:}

- Convenient online submission

- Rigorous peer review

- Open access: articles freely available online

- High visibility within the field

- Retaining the copyright to your article

Submit your next manuscript at $\boldsymbol{\nabla}$ springeropen.com 